Nina Goga

Høgskulen på Vestlandet

DOI: http://dx.doi.org/10.5617/adno.6447

\title{
Økokritiske litteratursamtaler - en arena for økt bevissthet om økologisk samspill?
}

\section{Sammendrag}

Høsten 2020 innføres nye lareplaner (LK20) i norsk skole. Noe av det nye i disse lcereplanene er innføringen av tverrfaglige temaer og kjerneelementer i alle fag. I denne artikkelen retter jeg oppmerksomheten mot det tverrfaglige temaet bærekraftig utvikling for å diskutere hvordan dette kan integreres i norskfaget med vekt på kjerneelementene tekst i kontekst, kritisk tilncerming til tekst og muntlig kommunikasjon.

Diskusjonen tar utgangspunkt i teoretiske perspektiver på økokritikk, litteratursamtaler og skalert lesing, og gjennom et forslag til hvordan lcerere kan legge til rette for økokritiske litteratursamtaler om representasjoner av forholdet mellom barn og trcer i to barnelittercere klassikere.

Artikkelen argumenterer for at denne koblingen mellom oppmerksom lesing av og samtaler om barnelitteratur kan utvikle kritiske perspektiver på verbalspråklige framstillinger av flersanselige naturerfaringer og dermed vcere et bidrag til økt bevissthet om økologisk samspill. Dette er kunnskap som kan ha betydning for hvordan barn og unge blir språklig rustet til å orientere seg i den overordnete klimadiskursen og for hvordan de vil forstå seg selv i rollen som økoborgere.

Nøkkelord: økokritikk, plantestudier, litteratursamtaler, barnelitteratur, Johanna Spyri, L. M. Montgomery

\section{Ecocritical literature conversations - An arena for increased awareness of ecological interplay?}

\section{Abstract}

By autumn 2020 a new national school curriculum (LK20) will be introduced in Norway. Some of what is new in LK2O is the introduction of cross-curricular themes and core elements in all school subjects. In this article I turn the attention to the cross-curricular theme sustainable development to discuss how this may be integrated into the school subject Norwegian and with a special emphasis on the core elements text in context, critical approach to text and oral communication. 
The discussion is based on theoretical perspectives on ecocriticism, literature conversations and scaled reading, and on a specific proposal for how teachers may prepare for ecocritical literature conversations on representations of the relationship between children and trees in two literary classics for children.

The article argues that this bridging between careful reading of and conversation about children's literature may evolve a critical approach to verbal depictions of multisensory nature experiences and hence contribute to increased awareness of ecological interplay. Such knowledge may prove significant to children's linguistic skills needed to orientate in the overall climate discourse and to how they understand themselves as ecocitizens.

Keywords: ecocriticism, plant studies, literature conversations, children's literature, Johanna Spyri, L. M. Montgomery

\section{Innledning}

Utgangspunktet for denne artikkelen er de læreplanendringene som norsk skole, og dermed også norsk lærerutdanning, vil stå overfor fra og med høsten 2020. Foruten innføringen av det som kalles kjerneelementer ${ }^{1}$, vil den nye læreplanen (LK20) inneholde tre tverrfaglige tema: folkehelse og livsmestring, demokrati og medborgerskap og bcrekraftig utvikling (Utdanningsdirektoratet, 2018a). Begrunnelsen for å innføre tverrfaglige tema er at det å «lære om et tema fra forskjellige faglige perspektiver skal gi bedre forståelse og kompetanse i det enkelte faget og på tvers av fag» (Utdanningsdirektoratet, 2018b). I denne artikkelen rettes oppmerksomheten mot temaet bærekraftig utvikling og mot hvordan dette temaet kan integreres i norskfaget med vekt på kjerneelementene tekst i kontekst, kritisk tilncerming til tekst og muntlig kommunikasjon (Kunnskapsdepartementet, 2018). ${ }^{2}$

Spørsmålet om hvordan bærekraftig utvikling kan integreres i norskfaget, blir forsøkt besvart ved å anlegge et økokritisk perspektiv på barnelitterære tekster og gjennom et forslag til økokritisk litteraturundervisning basert på strukturerte litteratursamtaler og skalert lesing. Det økokritiske perspektivet dreier seg her om å undersøke litterære framstillinger av naturrelasjonen mellom barn og trær i to barnelitterære klassikere, nærmere bestemt Johanna Spyris Heidi (2006, opprinnelig utgitt 1880) og Lucy Maud Montgomerys Anne fra Bjørkely (2014, opprinnelig utgitt 1908). Valget av de barnelitterære tekstene begrunnes med

\footnotetext{
${ }^{1}$ Kjerneelementer forklares som «det viktigste innholdet, og det elevene må lære for å kunne mestre og bruke faget. Det kan altså være kunnskapsområder, metoder, begreper, tenkemåter og uttrykksformer» (Utdanningsdirektoratet, 2017).

${ }^{2}$ Bærekraftig utvikling er i de nye læreplanene forstått i tråd med kortversjonen av Brundtland-kommisjonens definisjon av begrepet (World Commission on Environment and Development, 1987, s.18) som det «å ta vare på behovene til mennesker som lever i dag, uten å ødelegge fremtidige generasjoners muligheter til å dekke sine» (Utdanningsdirektoratet, 2018b).
} 
deres relevans i møte med kjerneelementene tekst i kontekst, kritisk tilnærming til tekst og muntlig kommunikasjon.

\section{Tidligere forskning}

Fagfeltet utdanning for bærekraftig utvikling (UBU) ${ }^{3}$ er utviklet på bakgrunn av FNs vedtak fra 2002 om at perioden 2005-2014 skulle være tiåret for utdanning for en bærekraftig utvikling. Denne utdanningen ble forstått som avgjørende for å nå de tusenårsmålene som FN formulerte i 2000. I 2015 erstattet FN tusenårsmålene med 17 bærekraftsmål (Sustainable Development Goals, SDGs) for perioden 2016-2030. Det fjerde bærekraftsmålet er God utdanning, og i delmål 4.7 rettes oppmerksomheten spesifikt mot skole og høyere utdanning som innen 2030 «skal sikre at alle elever og studenter tilegner seg den kompetanse som er nødvendig for å fremme bærekraftig utvikling, blant annet gjennom utdanning for bærekraftig utvikling og livsstil» (FN-sambandet, 2018, mål 4.7). I en norsk utdanningskontekst har ansvaret for at elever og studenter tilegner seg denne kompetansen, tradisjonelt vært lagt til samfunnsfag og naturfag og de tilhørende forskningsfeltene. Endringen som ligger i fagfornyelsen, der bærekraftig utvikling er ett av tre tverrfaglige temaer, innebærer at andre fag og forskningsfelt også får ansvar for at elever og studenter tilegner seg nødvendig kompetanse for å fremme bærekraftig utvikling.

Eksisterende fagbøker innenfor UBU, som Astrid Sinnes' Utdanning for bærekraftig utvikling. Hva, hvorfor og hvordan? (2015), insisterer på feltets tverrfaglighet, men gir ingen eksempler på hvordan arbeid med for eksempel barne- og ungdomslitteratur (norsk eller engelsk) kan ha en plass i denne utdanningen. For å søke kunnskap om hvordan arbeid med litteratur kan bidra til at elever og studenter tilegner seg nødvendig kompetanse for å fremme bærekraftig utvikling, kan man vende seg mot det litteraturorienterte fag- og forskningsfeltet økokritisk pedagogikk.

Selv om det internasjonalt har vært publisert flere bidrag innenfor «ecocritical pedagogy» (Garrard, 2012a, s. 2), så er det foreløpig publisert relativt lite om norskfagets potensial i arbeidet med kunnskap om og innsats for en bærekraftig utvikling. I tillegg til at den økokritiske pedagogikken har vært konsentrert rundt studenter i høyere utdanning og anglo-amerikansk litteratur for voksne lesere, har den, med enkelte unntak (James, 2012), også vært dominert av stedsbaserte feltundersøkelser av litteratur, altså en tilnærming til litteratur basert på lesernes førstehåndserfaring med det litterære landskapet (Garrard, 2012a). Flere av bidragene i antologien Teaching Environments. Ecocritical Encounters (Bartosch \& Grimm, 2014) kan leses som et supplement til og en problematisering av denne formen for økopedagogikk. Ikke minst gjelder dette balansen mellom «teaching

\footnotetext{
${ }^{3}$ På engelsk kalt Education for Sustainable Development (ESD) (UNESCO, u.å.).
} 
and preaching» eller mellom økokritikkens etiske dimensjon og humanioras vektlegging av oppøving i kritisk refleksjon. Ifølge Sieglinde Grimm (2014), en av redaktørene og bidragsyterne i boken, må økokritikk og økokritisk pedagogikk fokusere på «the relationship between man and nature as it is shown in literary texts» (s. 256). På den måten vil det også bli klart hva litteratur grunnleggende sett er, nemlig «a demonstration of basic cultural patterns of what we experience in our lives» (s. 256).

I noen grad kan vi si at internasjonal og nasjonal forskning som presenterer økokritiske lesninger av barne- og ungdomslitteratur, kan være et utgangspunkt for det vi kan kalle en økokritisk litteraturundervisning. ${ }^{4}$ Internasjonalt var det i første omgang det australske forskningsmiljøet som bidro til dette feltet (Massey, 2009; Massey \& Bradford, 2011; Curry, 2013; Flanagan, 2014), men senere har forskere fra andre miljø bidratt med sentrale artikler og verk (Bland, 2014; Bartosch, 2014; Ratelle, 2015; Jaques, 2015). I en nordisk sammenheng er det først og fremst miljøet knyttet til forskningsgruppen Nature in children's Literature and Culture ${ }^{5}$ ved Høgskulen på Vestlandet som har utviklet feltet, senest med den nordiske workshopen Ecocritical Perspectives on Nordic Children's and Young Adult Literature (oktober 2018). Blant nordiske forskningsbidrag finner vi lesninger av et bredt register barne- og ungdomslitterære tekster, som framstillinger av dyr og nærmiljø i bildebøker (Birkeland, 2016; Goga, 2017a), posthuman identitet i nyere ungdomslitteratur (GuanioUluru, 2017) og klassisk barnelitteratur (Ahlbäck, 2010; Goga, 2017b), natur i finsk barne- og ungdomslitteratur (Laakso, Lahtinen \& Heikkilä-Halttunen, 2011) og økokritiske perspektiver på nordisk barnelitteratur og kultur (Nilsson-Skåve, 2015; Iversen, 2016; Goga, Guanio-Uluru, Hallås \& Nyrnes, 2018; Goga, 2018b, 2018c; Wistisen, 2018).

Mens de økokritiske lesningene av barnelitteratur i mange tilfeller har dreid seg om de litterære framstillingene av kjæledyr, husdyr og ville dyr og av forholdet mellom mennesker og dyr, så har relativt få (Guanio-Uluru, 2018, 2019; Goga, 2017b) utforsket framstillinger av planter og av forholdet mellom mennesker og planter i barnelitterære tekster. ${ }^{6}$ Behovet for å fylle ut dette kunnskapsfeltet kan ses i sammenheng med flere av FNs uttalte bærekraftsmål (FN-sambandet, 2018), som målet om å utrydde sult (mål 2), målet om bærekraftige byer og samfunn (mål 11), og ikke minst målet om å «beskytte, gjenopprette og fremme bærekraftig bruk av økosystemer, sikre bærekraftig

\footnotetext{
${ }^{4}$ Det skal nevnes at de siste årene har også det allmennlitteraturvitenskapelige forskningsfeltet i Norden bidratt med økokritiske perspektiv, spesielt i forbindelse med lyrikk (Larsen, Mønster \& Rustad, 2017). Det er også blitt etablert et økokritisk nettverk for skandinaviske studier (ENSCAN), som arbeider med «environmental topics related specifically to the literatures and cultures of the Nordic countries» (ENSCAN, u.å.). Nettverkets arbeid har foreløpig resultert i publikasjonen Nordic Narratives of Nature and the Environment. Ecocritical Approaches to Northern European Literatures and Cultures (Hennig, Jonasson \& Degerman, 2018), der et av bidragene omhandler en barnelitterær tekst (Goga, 2018b).

${ }^{5}$ Se forskningsbloggen https://blogg.hvl.no/nachilit/ .

${ }^{6}$ Hanna Samola (2018) har utforsket møter mellom mennesker og planter i nyere finske dystopier for voksne.
} 
skogforvaltning, bekjempe ørkenspredning, stanse og reversere landforringelse samt stanse tap av artsmangfold» (mål 15).

Når det gjelder mer eksplisitte undersøkelser av eller innspill til hvordan norskfaget aktivt kan engasjere seg i klimaspørsmål og utfordringer knyttet til bærekraftig utvikling, er antallet publikasjoner ennå beskjedent. Nina Goga gjorde i 2016 en undersøkelse av ungdomsskoleelevers møte med det hun kaller en klimalitterær bildebok (Goga, 2016) og bidro teoretisk med et kapittel om bærekraftig litteraturundervisning (Goga, 2018a) i en ny lærebok rettet mot 1.-7. trinns lærere og lærerstudenter. Jonas Bakken (2018) drøfter muligheter og utfordringer med økokritisk litteraturdidaktikk med utgangspunkt i ungdoms- og fantasyromanen Mellom verdener (2014) av Máret Ánne Sara. Og med utgangspunkt i Ruth Lillegravens diktsamling Eg er eg er eg er (2016) argumenterer Marianne Røskeland (2018) for at en økokritisk litteraturundervisning ikke trenger å gå på bekostning av gode leseopplevelser eller arbeid med litterær kompetanse.

Røskeland har også tidligere vært opptatt av litteraturens plass i skolen og hva, hvordan og hvorfor det leses (Røskeland, 2014). Utgangspunktet den gang var blant annet en bekymring for at det teoretiske danningsaspektet ved litteraturundervisningen tapte terreng til fordel for en litteraturundervising der litteratur er «ein reiskap for utvikling av funksjonell leseferdigheit» (Røskeland, 2014, s. 204). Liknende bekymringer eller problematiseringer finner vi i Hallvard Kjelens (2013) avhandling om litteraturundervisning i ungdomsskolen og i Sylvi Pennes (2012) nordiske undersøkelse av hva lærere i videregående skole mener vi trenger litteraturen til. I et nyere forskningsbidrag om barneskolelæreres tanker om litteraturens plass i skolen uttrykker Siri Hovda Ottesen og Aasfrid Tysvær (2017) bekymring for en annen tendens, nemlig at litteraturen bare er der «for kosens skyld». Ottesen og Tysvær argumenterer derfor for at det er behov for mer felles oppmerksomhet og arbeid rundt litterære tekster. I den sammenheng nevner de at utforskende lesemåter og litterære samtaler som involverer elevene, «kan åpne opp tekster og gi elevene litterær kompetanse og fremme kritisk literacy» (s. 64).

Denne artikkelen plasserer seg i forlengelsen av den økokritiske pedagogikkens grunntanke om at litteraturen kan vise oss de grunnleggende kulturformete mønstrene som vi erfarer livet gjennom, spesielt slik denne grunntanken er blitt undersøkt i de mange økokritiske analysene av barne- og ungdomslitteratur. Men artikkelen plasserer seg også i forlengelsen av de forskningsbidragene om litteraturdidaktikk i norskfaget som hevder at litteratursamtalen kan utvikle både økologisk og litterær bevissthet. Ved å kombinere den økokritiske pedagogikken og litteratursamtalen ønsker jeg å vise hvordan elever, gjennom litteraturmøter i en norsk utdanningskontekst, kan tilegne seg kunnskap og kompetanse som fremmer økologisk bevissthet og bærekraftig utvikling. Jeg skal derfor nå se nærmere på hva som kjennetegner litteratursamtalen og på hva det vil si at den er økokritisk. 


\section{Teoretiske perspektiver: økokritikk, litteratursamtale og skalert lesing}

I The Ecocriticism Reader forklarer Cheryll Glotfelty (1996) økokritikk som studiet av forholdet mellom litteratur og de fysiske omgivelsene (s. xviii). I tillegg understreker hun at «ecocriticism takes an earth-centered approach to literary studies» (s. xviii). En annen sentral referanse i forlengelsen av Glotfelty er Greg Garrard (2012b) som forklarer økokritikk som en litterær eller kulturell analyse av miljøspørsmål og av det kulturhistoriske forholdet mellom «the human and the non-human» (s. 5). Det finnes flere økokritiske retninger, ofte avhengig av hva som er det spesifikke studieobjektet, som for eksempel studier av ulike forståelser av dyr i litterære tekster (animal studies), eller framstillinger av framtidige klimakriser (cli-fi).

For å diskutere naturrelasjonen mellom barn og trær i Heidi og Anne fra Bjørkely kan det være fruktbart å trekke veksler på nyere plantestudier (plant studies). Innenfor økokritikken kan plantestudier ses på som både en videreføring og en komplettering av det mer etablerte forskningsfeltet animal studies. Michael Marder (2013, s. 2) hevder at

[if] animals have suffered marginalization throughout the history of Western thought, then non-human, non-animal living beings, such as plants have populated the margin of the margin, the zone of absolute obscurity undetectable on the radar of our conceptualities.

Marder er opptatt av hvordan det er mulig for oss å møte og samhandle med planter og av hvordan vi kan «maintain and nuture, without fetishizing it, their otherness in the course of this encounter» (s. 3). For Marder er svaret det han kaller plant-thinking, en tenkning basert på hermeneutisk fenomenologi, dekonstruksjon og såkalt svak tenkning (s. 7) der «plant-thinking situates the plant at the fulcrum of its world» (s. 8).

Mens Marder undersøker hvordan planter er forstått gjennom filosofihistoriens tekster, er Randy Laist (2013) opptatt av nødvendigheten av å undersøke hvordan forholdet mellom mennesker og planter formidles litterært. Laists utgangspunktet for antologien Plants and Literature. Essays in Critical Plant Studies (2013) er at planter spiller en avgjørende rolle «in the experience of being human» (s. 9) og at planter lever blant oss som «fellow species» (s. 9). Av den grunn er det interessant å undersøke hvordan menneske-plante-relasjoner er framstilt i ulike litterære tekster. En slik måte å forstå planters nærvær i verden på, innebærer også å forstå planter som sansende skapninger. I boken What $a$ Plant Knows undersøker Daniel Chamovitz (2012) hva planter ser, lukter, hører og føler, men denne bruken av sansebegreper som vanligvis er reservert dyr (mennesket inkludert), har ikke som hensikt å antropomorfisere planter, heller «challenge us to think in new ways about sight, smell, what a plant is, and ultimately what we are» (Chamovitz, 2012, s. 5). 
I vår sammenheng kan en tilnærming til framstillinger av møtene mellom barn og trær i Heidi og Anne fra Bjørkely legge grunnlag for samtaler og refleksjon rundt ulike syn på trær og ulike erfaringer med trær, men også rundt språklige framstillinger av slike møter og erfaringer. Koblet til FNs bærekraftsmål nummer 15 dreier dette seg om å utvikle forståelse for trærs rett til liv og for nødvendigheten av å gjenopprette «en bærekraftig forvaltning av all slags skog, stanse avskoging, gjenopprette forringede skoger og i betydelig grad øke skoggjenreising og nyplanting på globalt nivå» (FN-sambandet, 2018, mål 15.2). Å legge til rette for denne typen refleksjon er nettopp hensikten med den økokritiske litteratursamtalen.

Innenfor en litteraturdidaktisk praksis blir litteratursamtaler sett på som én av flere måter å skape mening med tekst på. Internasjonalt er det teoretisert over og forsket både i og utenfor klasserommet på det som kalles bokklubber, boksamtaler og litteratursirkler, der den siste varianten nok er den som har fått størst tilslutning i en klasseromskontekst. ${ }^{7}$ Den største forskjellen mellom litteratursirkler og litteratursamtaler er at man i litteratursirklene tildeles særlige leserroller, som for eksempel at én har ansvar for å velge ut viktige ord, en annen sentrale passasjer og en tredje skal forberede overordnete refleksjonsspørsmål (Daniels, 2002). I en norskfaglig kontekst står trolig litteratursamtalen sterkere enn litteratursirkelen. Det er særlig Laila Aases artikkel Littercre samtalar (2005), men også Åsmund Hennigs innføringsbok Effektive lesere snakker sammen (2012), det vises til når man skal gjøre nærmere rede for hva som kjennetegner litteratursamtalen. Aase forklarer litteratursamtalen som en klassesamtale «som uttrykkjer leseerfaringar og som har som føremål å undersøkje litterære tekstar med utgangspunkt i desse erfaringane» (Aase, 2005, s. 106). Samtalen gir rom for at ulike stemmer (elevens, tekstens, lærerens) møtes og forhandler om lesemåter av den aktuelle teksten. Men samtalen kan også, ifølge Goga (2016), utvikle elevene til deltakere i andre framtidige tolkningsfellesskap som for eksempel kan dreie seg om hvordan forstå en felles verden eller hvordan formulere en felles tekst om verden. Et liknende syn på litteratursamtalen som en mulig danningsarena finnes også i Gro Ullands (2016) undersøkelse av litteratursamtaler med elever på mellomtrinnet.

Et viktig trekk ved den litterære samtalen er at den er en institusjonsbundet, formell og iscenesatt sjanger, og at den skiller seg fra mer dagligdagse og uformelle samtaler (Aase, 2005, s. 108). Selv om den litterære samtalen skal være konsentrert om den litterære teksten og det er teksten som skal styre hva det er rimelig å uttale seg om, så vil læreren også være styrende når hen, for eksempel gjennom ulike lesebestillinger, retter lesernes blikk mot utvalgte tekststeder. En lesebestilling (Kverndokken, 2012) kan være å be elevene notere favorittsitater eller tekststeder med et bestemt innhold, illustrere en bestemt passasje med egne eller andres bilder, eller å streke under forekomsten av bestemte ord. Ved hjelp av

\footnotetext{
${ }^{7}$ I en norsk skolekontekst har litteratursirkler vært anbefalt som arbeidsmåte i forbindelse med litteraturundervisning i engelskfaget (Rimmereide, 2013, s.154). Lykke Guanio-Uluru (under utgivelse) har også prøvd ut det hun kaller Eco-Critical Literature Circles med en gruppe norske lærerstudenter som tok engelsk som valgfag.
} 
det Alice Curry (2017) omtaler som skalert lesing (scaled reading) kan man bli bevisst på hvilke nivå i teksten og i forholdet mellom tekst og leser man ønsker å rette blikket mot i lesebestillingen.

Curry ser skalert lesing som et alternativ til en mannsdominert tenkning som på tvers av kulturer og opp gjennom historien har neglisjert kvinner og barn så vel som de fysiske omgivelsene i jakten på makt. Denne kontrollerende og marginaliserende diskursen har ifølge Curry medvirket til den miljø- og klimakrisen som vi i dag erfarer (Curry, 2017, s. 70). Curry mener at ved å lese skalert kan andre sider ved klimadiskursen enn den makroøkonomiske komme til uttrykk. Grovt skissert er det snakk om tre skaleringer: «small-scale personal transformation; medium-scale socio-political change; and large-scale environmental reappraisal» (s. 74). I sammenheng med den økokritiske litteratursamtalen kan små-skala-lesing innebære at man i samtalen retter oppmerksomheten mot hvordan tekstene framstiller de barnelitterære karakterenes sanselige naturerfaringer. Mellom-skala-lesing kan sette disse erfaringene inn i en sosiopolitisk og kulturell sammenheng, som hvordan forholdet mellom ulike arter og livsformer presenteres og vurderes, og en stor-skala-lesing kan rette oppmerksomheten mot naturerfaringers plass i et overordnet økologisk eller bærekraftig perspektiv. Tanken er at gjennom den økokritiske litteratursamtalens forhandling om mening skal den skalerte lesningens ulike målestokker kunne forsterke og utfylle hverandre snarere enn nulle hverandre ut.

Denne typen økokritisk litteratursamtale innebærer ikke bare oppmerksom lesing av litterær tekst og aktiv lytting til de andre deltakerne i samtalen. Litteratursamtalen som meningsutveksling eller forhandling om mening, innebærer også at lesernes tenkning møtes, at egen tenkning flettes med andres tenkning. Den økokritiske litteratursamtalen kan derfor også ses i sammenheng med Neil Mercers begrep om interthinking (Mercer, 2000, s. 1). I boken Words and Minds: How We Use Language to Think Together er han opptatt av at det har vært skrevet mye om forholdet mellom språk og tenkning, men ikke om vår bruk av språket for å tenke sammen «for collectively making sense of experience and solving problems» (Mercer, 2000, s. 1). Det i fellesskap å bli oppmerksomme på hvordan natur, naturerfaring og -forståelse er formet i eller formes av språk, må være av stor betydning for all utdanning for bærekraftig utvikling. Språket vi tenker med og utveksler meninger $\mathrm{i}$, er formet av en lang rekke tekster (verbale så vel som visuelle), samtaler og fagfelt. Å ikke være oppmerksom på hvordan vi sanser, snakker eller formulerer oss om natur eller hvor vi henter vårt språklige repertoar fra, vil kunne forkludre arbeidet med i fellesskap å oppnå bærekraftsmålene. For å bli mer konkret kan vi si at om vi har svært ulike erfaringer med verbale og visuelle uttrykk for og oppfatninger av for eksempel trærs verdi, vil det kanskje være ulike meninger om hvorvidt vi skal verne ulike tresorter og skoglandskap. 


\section{Begrunnelse for valg av barnelitterære eksempler}

Når Utdanningsdirektoratet i utkast til LK20 beskriver hvordan fagene engelsk og norsk kan bidra med faglige perspektiver på det tverrfaglige temaet bærekraftig utvikling, knyttes det i engelsk noe vagt til det «å arbeide utforskende og kritisk med et tekstmangfold» (Utdanningsdirektoratet, 2018b). Også i norsk knyttes tekstmangfold, kritisk lesing og dialog til temaet bærekraftig utvikling og til det å «utvikle respekt for det å være annerledes og lære å samhandle, virke og utfolde seg i et variert miljø» (Utdanningsdirektoratet, 2018b). En overordnet presisering tydeliggjør at elevene skal utvikle denne forståelsen for «samspillet mellom mennesket og dets livsbetingelser» gjennom arbeid med språk og litteratur i norskfaget (Utdanningsdirektoratet, 2018b). Med kritisk lesing og språklig oppmerksomhet kan med andre ord fagene norsk og engelsk bidra aktivt til å videreutvikle fagfeltet utdanning for bærekraftig utvikling. ${ }^{8}$

Som nevnt innledningsvis begrunner jeg her valget av litterære tekster til en mulig litteratursamtale med utgangspunkt i det nye norskfagets kjerneelementer, nærmere bestemt tekst i kontekst, kritisk tilnærming til tekst og muntlig kommunikasjon (Kunnskapsdepartementet, 2018).

Det første kjerneelementet, tekst i kontekst, innebærer blant annet å lese tekster, for eksempel barnelitterære tekster, fra andre språkområder og fra andre kulturhistoriske kontekster, men kan også motivere for en tilnærming til tekst som ser denne i sammenheng med samfunnsutfordringer på tvers av språk og historie. Vi kan med andre ord foreslå at det er en mulig sammenheng mellom kjerneelementet tekst i kontekst og Currys stor-skala-lesemåte.

Å lese tekster i kontekst kan helt konkret innebære å bli kjent med litterære klassikere. At en tekst får status som klassiker, det vil si blir regnet som en del av et større eller mindre samfunns felles kultur, kan skyldes ulike prosesser (Kidd, 2011). Det kan være at tekstens suksess og kommersielle potensial gjør den aktuell i typiske klassikerserier rettet mot nye generasjoner av lesere. Men det kan også være at tekster forvaltes i andre kretsløp, som for eksempel skole og bibliotek, fordi de anses som estetisk slitesterke og som gode tekstmodeller for ulike verdier, som for eksempel barns forhold til og væremåte i naturen.

Når det gjelder Heidi og Anne fra Bjørkely, kan deres klassikerstatus blant annet leses ut av den innflytelse disse tekstene har hatt på andre forfattere og forekomsten av skjulte eller direkte referanser i senere bøker. Når det skjer, går disse tekstene også i dialog med hverandre og åpner slik sett for forhandlinger på tvers av språk, samfunn og historie om nettopp ulike natur- og verdisyn. A løfte fram disse forhandlingene vil også kunne innebære å løfte fram overordnete økologiske og bærekraftige perspektiver.

\footnotetext{
${ }^{8}$ Beskrivelsen av temaet bærekraftig utvikling i fagene engelsk og norsk er hentet fra læreplanutkastet som hadde innspillfrist i april 2018. Beskrivelsen var også med i utkastet med innspillfrist i november 2018, men ble så strøket i utkastet med høringsfrist i juni 2019. I skrivende stund er det ennå uvisst hvordan endelig versjon av LK20 vil bli.
} 
Et nyere eksempel på hvordan boken om Heidi blir aktualisert og fortolket på ny finner vi i Maria Parrs Tonje Glimmerdal (2009). I likhet med Spyris Heidi handler også Parrs bok om en jente med sterk tilhørighet til det lille stedet hun bor på og om hennes strev med å forstå sin plass der og med å forene mennesker som lenge ikke har villet forholde seg til hverandre. Når det gjelder Anne fra Bjørkely, er det kanskje først og fremst gjennom Astrid Lindgrens forfatterskap og biografi at boken har hatt innflytelse i nordisk sammenheng. ${ }^{9}$ Flere av Lindgrens karakterer, men kanskje særlig Pippi og Ronja, henter trekk fra hovedpersonen Anne, som det røde, ofte viltre håret, den skarpe tungen og den sanselige nærheten til naturen og landskapet rundt hjemmet. ${ }^{10}$

Når bøker blir klassikere og virker i kulturen, betyr det at de forestillinger og verdier som etableres der, videreføres og kanskje utfordres gjennom nye leseres møter med dem. Det andre kjerneelementet, kritisk tilnærming til tekst, handler nettopp om at tekster ikke er nøytrale, og at måtene vi uttrykker oss på, verbalt og visuelt, etablerer, bygger og forvalter ulike forestillinger om verden, blant annet hvilke forestillinger vi har om natur og andre livsformer. Vi kan igjen se en forbindelse mellom det nye norskfagets kjerneelement og Currys skalerte lesemåter. Kjerneelementet kritisk tilnærming til tekst kan, avhengig av detaljnivået i den kritiske tilnærmingen, kobles til så vel små- som mellomskalerte lesemåter.

I både Heidi og Anne fra Bjørkely har kontakten mellom mennesker og trær vesentlig betydning for hovedpersonenes utvikling og danning, ikke minst deres etiske danning og deres utvikling av en særlig naturfølelse. Mange tidligere studier har interessert seg for ulike faktorer i identitetsdanningen i de to bøkene (f.eks. Bache-Wiig, 2010; McKenzie, 2013), men ingen har tidligere studert dem i et økokritisk perspektiv med vekt på hvordan framstillingene av de to jentenes relasjon til trær former deres, og potensielt også lesernes, Umwelt- eller omverdenforståelse.

Det tredje kjerneelementet, muntlig kommunikasjon, handler om evnen til å uttrykke seg og om evnen til å lytte både til andre og til tekster, og, kan vi kanskje legge til, til andre livsformers uttrykksregister. I en videre utdanningsforskningskontekst kan dette kjerneelementet ses i sammenheng med begrepet dialogisk undervisning som blant annet argumenterer for at klassesamtaler skal være kollektive, gjensidige, støttende, kumulative og meningsfulle (Alexander, 2008, s. 28). Dette er perspektiver på samtalen som også er konstituerende for litteratursamtalen som nettopp foregår innenfor rammene av en kollektiv litteraturlesing der evnen til samspill og aktiv lytting vektlegges (Aase, 2005).

En mulig innvending mot valget av eksempler kan være at de begge har jenter som hovedkarakterer. Det bør derfor legges til at det i det to bøkene også finnes

\footnotetext{
${ }^{9}$ Det kan nevnes at svensk var det første språket boken ble oversatt til og det så tidlig som i 1909, altså året etter at den ble utgitt på originalspråket.

${ }^{10}$ I artikkelen Enebarn eller littercert søsterskap? Om Heidi, Pippi og Tonje viser Goga (2011) til flere intertekstuelle tråder mellom disse bøkene.
} 
guttekarakterer som kontrasterer og utfordrer jentene, også de med egne tilnærminger til sine omgivelser. Når jeg i forslaget til hvordan det kan legges til rette for økokritiske litteratursamtaler om de to bøkene, vektlegger trærnes rolle i samspillet mellom mennesket og natur, vil noen kanskje hevde at jeg overser andre, mer betydningsfulle momenter som hvilken rolle kjønn, generasjonsmøter, skolesystemet eller sosial status kan spille for forståelsen av boken. Jeg mener selvsagt ikke at det ene behøver å utelukke det andre, men jeg mener, også med henvising til nyere barnelitteratur, at relasjonen barn-trær foreløpig er lite utforsket uansett om perspektivet er økokritisk eller kjønnsteoretisk.

Jeg utelukker heller ikke at andre, og gjerne nyere, barnelitterære tekster kan egne seg som utgangspunkt for økokritiske litteratursamtaler der oppmerksomheten rettes mot naturrelasjonen mellom barn (både gutter og jenter) og trær. Her skal bare kort nevnes Eva Lindströms bildebok I skogen (2008), Stian Holes bildebok Morkels alfabet (2015), Lene Asks ordløse bildebok Du (2016) og Heidi Sævareids roman Bruddlinjer (2017). Til slutt vil jeg legge til at det ikke trenger å være et kriterium for valg av bok til en økokritisk litteratursamtale at den har et uttalt økologisk perspektiv. Det kan snarere være like interessant å lese tekster som ikke nødvendigvis rommer et slikt perspektiv for å likevel se nærmere på hvordan et eventuelt samspill mellom menneske og natur er framstilt i teksten og på hvilke verdier og natursyn som fremmes gjennom denne framstillingen.

\section{Økokritiske litteratursamtaler om møter mellom mennesker og trær - et forslag}

I denne artikkelen interesserer jeg meg som nevnt for hvordan barneleseren gjennom økokritiske litteratursamtaler kan rette oppmerksomheten mot framstillingen av kontakten mellom mennesker og trær i to barnelitterære klassikere, og for hvordan slike samtaler kan legge til rette for at deler av FNs bærekraftsmål oppfylles (mål 4.7), formidles og diskuteres (mål 15) gjennom norskfaget. Før jeg går nærmere inn på den økokritiske litteratursamtalen i norskfaget, tar jeg for meg noen av de mange eksemplene på hvordan den flersanselige kontakten mellom mennesker og trær framstilles i Heidi og Anne fra Bjørkely. Målet er her å konkretisere og synliggjøre hvordan disse to klassikerne egner seg til å eksemplifisere en slik kontakt.

Undervisningsforslaget jeg så legger fram, er inspirert av økokritiske perspektiver og forholder seg aktivt til kjennetegn ved litteratursamtalen slik det er redegjort for ovenfor, samt Currys forståelse av skalert lesing. I tillegg forankres forslaget i dagens norskfag med henvisning til de nye kjerneelementene tekst i kontekst, kritisk tilnærming til tekst og muntlig kommunikasjon, også de omtalt i artikkelens første del. Utover dette er vurderingene som ligger til grunn for forslaget preget av egne erfaringer fra litteraturdidaktiske praksiser i grunnskole og i lærerutdanningen. 
Alt i første setning i Heidi nevnes det at landskapet rundt landsbyen består av «grønne skogsletter» (Spyri, 2006, s. 5), og det innledende avsnittet fortsetter med å lede leseren opp dalsiden til lyngheier og fjellblomster som «dufter av krydder mot den som kommer» (s. 5, min kursiv). Bokens første kapittel fortsetter så i en vekselvirkning mellom en beskrivelse av menneskene som er på vei opp dalsiden og bakgrunnshistorien for deres ankomst, og en beskrivelse av landskapet de beveger seg oppover i. Når de til slutt ankommer flaten der Heidis bestefar bor og der Heidi skal avleveres, møter leseren et sted «utsatt for vær og vind» der «hver eneste solstråle» når fram og med en «prektig utsikt langt ned i dalen» (s.17-18). Etter denne panorereringen stilles teksten et øyeblikk skarpt før den zoomer ut igjen: «Bak hytta stod tre gamle grantrær med tette, lange grener. Bak dem bar det videre oppover mot fjellet» (s. 18). Det er ingen tilfeldighet at leseren gjøres ekstra oppmerksom på de tre grantrærne. Alt i andre kapittel blir det tydelig at Heidi kommer til å knytte en særlig kontakt med disse trærne: «Hun fortsatte å se seg rundt og kom til de gamle granene bak hytta. Da blåste vinden så sterkt gjennom baret at det suste og bruste oppe i tretoppene. Heidi stod stille og lyttet» (s. 21, min kursiv). Gjentatte ganger i løpet av fortellingen er det trærne Heidi oppsøker, lytter til og lengter etter (i byen), og som hun oppfatter som emblematisk for hele stedet.

Mens leseren ankommer bestefarens hus samtidig med Heidi, blir leseren av Anne fra Bjørkely kjent med Bjørkely før Anne selv kommer dit. Siden leserens første møte med Bjørkely skjer gjennom nabokonen fru Rachels kritiske blikk på stedet, blir trærne i området sett på med skepsis. Fru Rachels dom over det aldrende søskenparet Matthew og Marilla, som skal bli Annes fosterforeldre, skjer gjennom en sammenstilling med trær. Ifølge fru Rachel bare eksisterer Matthew og Marilla i stedet for å leve. At de er litt rare, mener hun har sammenheng med Bjørkelys avsidesliggende beliggenhet. Hun konkluderer med at «[d]et er ikke mye selskap i trær, skjønt om det så hadde vært, er det i det minste nok av dem» (Montgomery, 2014, s. 10). Når Matthew i bokens andre kapittel drar for å hente fosterbarnet de har ventet på (altså Anne), endrer blikket på stedets trær seg radikalt. Gjennom Annes begeistrete utbrudd blir Matthew, og leseren, stadig gjort oppmerksom på de blomstrende kirsebærtrærne, duftende eplehager, ville plommetrær og hvite bjørketrær. Og den pratsomme Anne, som alltid er opptatt av om nye steder har rom for hennes fantasier, blir til slutt helt stum i møtet med landskapet hun reiser gjennom. Det siste hun hvisker før hun sovner den første natten, viser at også Anne evner å sanse og lytte til trær: "'Hør hvordan trærne snakker i søvne, [...] De drømmer sikkert søte drømmer!'» (s. 30, min kursiv). De mange sansedetaljerte skildringene av Heidi og Annes ankomst til stedene de skal knytte seg så sterkt til, kan kanskje også legge et viktig grunnlag for leserens egen stedsforståelse og for hvordan hen sanser og erfarer natur.

Denne mulige sammenhengen, eller dialogen, mellom hvordan vi forstår og erfarer natur og steder i egne liv og de kulturelt formidlete tankefigurene om naturerfaringer som vi kan erfare gjennom litteratur, er noe den retorisk orienterte 
økokritikken og økopedagogikken har vektlagt. Litterære klassikere kan være bærere av måter å formulere en omverdenforståelse på som blant annet kan ha innflytelse på hvordan vi fortsetter å skrive og snakke om naturerfaringer. Måtene vi skriver og snakker om naturerfaringer på, legger i neste omgang premisser for hvordan vi ønsker at våre omgivelser skal bevares eller gjenskapes.

I tillegg til bøkenes klassikerstatus og hovedpersonenes sansebaserte naturoppmerksomhet er det også komposisjonelle fellestrekk ved Heidi og Anne fra Bjørkely. Her skal kort nevnes at jentenes ankomst skyldes at de begge er foreldreløse og trenger å bli tatt vare på av voksne. De voksne er ikke udelt komfortable med den nye omsorgssituasjonen og en del av historien handler om hvordan barnet gir ny mening til stivnete voksenliv. Til slutt skal det også nevnes at de to jentene må tilbringe tid vekke fra sine nye hjem, nærmere bestemt i byen, og at erfaringene med bylivet forsterker deres ønske om å bo henholdsvis på Bjørkely og i dalsiden ovenfor alpelandsbyen. Det at Anne og Heidi så tydelig utvikler en kjærlig stedsfølelse, endrer og utvikler ikke bare dem selv, men også stedet og andres følelse for stedet. Outsideren får insideren til å se seg selv og stedet på nytt.

I det skisserte forslaget konsentrerer jeg meg om den litterære teksten og om hvordan elevene kan veiledes av lesebestillinger fra læreren. Det økokritiske viser seg i vektleggingen av skalert lesing som gjør elevene bevisst på tekstens ulike nivå. Forslagene til lesebestillinger fokuserer på oppmerksom lesing av den litterær teksten så vel som aktiv lytting til de andre i samtalen for at lesernes tenkning skal møtes i en felles meningsskaping.

Forslaget har som utgangspunkt at de tenkte leserne befinner seg på mellomtrinnet (5.-7. trinn) i den norske grunnskolen. Dette alderssegmentet er valgt av særlig to grunner. For det første fordi bøkene er nokså lange og krever enten lesere som selv kan ta seg gjennom dem på egen hånd, eller kan holde fokus i en eventuell høytlesning av fortellinger som strekker seg ut i både tid og rom. For det andre er de litterære karakterene noenlunde på samme alder som elever på mellomtrinnet. I begynnelsen er Heidi riktignok noe yngre, men i løpet av fortellingen utvikler hun et modenhetsnivå tilsvarende elever på 5. trinn.

Selv om de to bøkene her behandles parallelt, betyr det ikke at de må leses og arbeides med parallelt. De kan selvsagt leses hver for seg eller de kan leses i sammenheng med andre, gjerne nyere, barnelitterære eksempler. Vi kan for eksempel se for oss en økokritisk litteratursamtale som sammenlikner hvordan Spyris Heidi og Parrs Tonje sanser og erfarer sine omgivelser, eller en økokritisk samtale som sammenlikner barnekarakterens forhold til trær i Montgomerys Anne fra Bjørkely og Asks Du.

Elevenes første møte med de aktuelle tekstene behøver ikke å begynne med de valgte utgavene. ${ }^{11}$ For å åpne samtalene om hvem bøkene handler om (utseende,

\footnotetext{
${ }^{11}$ Både Heidi og Anne fra Bjørkely er publisert på norsk i en rekke utgaver med ulike oversettelser. Det inne-
} bærer blant annet at ikke alle de norske utgavene alltid har oversatt hele teksten. I de utgavene der teksten er 
kjønn, alder, relasjoner) og i hvilke omgivelser handlingen foregår, kan elevene få møte de ulike forsidene på en rekke eldre og nyere utgaver av de to bøkene. Vi kan gjerne forstå denne måten å nærme seg bøkene på som en form for mellomskala-lesing der tanken er at elevene ser forsidene og de ulike utgavene i en større kulturell sammenheng. Her vil det også være rom for å forstå den didaktiske tilnærmingen i lys av kjerneelementet kritisk tilnærming til tekst (er det for eksempel forskjell mellom hvordan Heidi og Anne framstilles som jenter på de ulike forsidene?), men også kjerneelementet tekst i kontekst fordi ulike utgaver og ulike utgivelsestidspunkt åpner for refleksjon og samtale om hva det kan være ved disse bøkene som har gjort at de blir utgitt på nytt (altså hva som har gitt bøkene status som klassiker).

De ulike utgavene av Heidi viser henne som regel med fjell i bakgrunnen og ofte barføtt sammen med bestefarens geiter og/eller med bestefaren. Også i mange av utgavene av Anne fra Bjørkely viser forsiden en jente i et landlig miljø. Det kan noen ganger være utydelig om Anne befinner seg innendørs eller utendørs. Ofte er omgivelsene utendørs synlige gjennom en dør eller et vindu. Gjennom observasjon, sammenlikning og deling av synspunkter i fellesskap vil elevene kunne avdekke mange av disse forholdene og på den bakgrunn både forberede seg på fortellingene de skal møte og lage hypoteser, som siden kan testes og revideres, om hva som vil skje i disse fortellingene.

For at elevene skal få anledning til selvstendig og kritisk å kunne observere og sammenlikne forsidene, kan de alt fra starten av introduseres for ett av litteratursamtalenes viktigste arbeidsredskaper - leseloggen. Leseloggen er en privat og uformell papirbasert eller digital notatbok der elevene samler all tenkeskriving (Skrivesenteret, 2013), alle stikkord og alle skisser (verbale som visuelle) som de skaper i løpet av litteratursamtaleperioden. Tenkeskriving er ment å være utforskende og fungere som støtte for og klargjøring av egne tanker (Håland, 2016, s. 21) og kan derfor være et egnet utgangspunkt for videre muntlig meningsutveksling, eller interthinking, det være seg deling i par eller i større grupper eller i gruppen som helhet.

I det videre arbeidet med bøkene kan det veksles mellom høytlesing, lesing i par, lesing på egen hånd, hjemme eller på skolen. Det er også mulig å tenke seg at deler av bøkene kan lyttes til på lydbok (en løsning som selvsagt vil kunne gjelde hele boken). Det vil være hensiktsmessig å la elevene selv lese, eller bli lest høyt for, de to første kapitlene i bøkene der jentenes ankomst til sine nye hjem skildres. Elevene kan få i lesebestilling å notere stikkord knyttet til landskapet de to jentene forflytter seg i. Her kan de oppfordres til å veksle mellom å notere både overordnete observasjoner og enkeltord eller formuleringer. Når elevene etter lesing og etter å ha notert deler sine observasjoner med hverandre, er det viktig at det gis rom for å gå til tekstene for å finne fram aktuelle tekstpassasjer, gjerne lese dem høyt på nytt og stille blikket skarpere på nye detaljer. Å jobbe med

forkortet, er det vanligvis karakterskildringer og naturbeskrivelser som er utelatt. For økokritiske litteratursamtaler om de to bøkene er det viktig å være seg bevisst hvilke utgaver av teksten man har tilgang til. 
observasjon og sammenlikning med utgangspunkt i lesebestillinger kan knyttes til kjerneelementet kritisk tilnærming til tekst. At tilnærmingen er kritisk, må forstås som at den er konsentrert og granskende helt ned på tekstens detaljnivå (som ord og metaforer), men også at den gjennom sammenlikning kan avdekke tvetydigheter og forskjeller som løftes fram i samtalene og gjøres til gjenstand for meningsutveksling og forhandling.

Med utgangspunkt i et knippe observasjoner fra lesingen av de to første kapitlene kan læreren, i forkant av elevenes møte med de neste kapitlene, be dem om å legge særlig merke til liknende samspill mellom de to hovedkarakterene og deres omgivelser - og kanskje, hvis det ikke finnes blant elevenes observasjoner, be dem med henvisning til konkrete sitater i de første kapitlene om å finne eksempler på hvordan karakterene er oppmerksomme på trærne der de bor. Både karakterenes og elevenes oppmerksomme blikk for trær kan legge til rette for det Marder (2013) omtalte som plantetenkning og for samtaler der litterære sansemøter med trær kan gjøre leserne mer bevisste på sin egen omverdenforståelse og hvordan de formulerer seg om den.

Etter hvert som elevene blir fortrolige med tekstene, med dynamikken i litteratursamtalen og med det økokritiske perspektivet, kan de selv få anledning til å notere ord, formuleringer og avsnitt som gjør særlig inntrykk på dem. Dette åpner for en mer personlig involvering i teksten. Det personlige engasjementet med naturrepresentasjoner i tekst kan også bevege elevene i retning av deres eget engasjement eller mangel på engasjement og forhold til natur, og i denne sammenheng særlig deres forhold til trær. Hvilke trær kjenner de til? Hvilke trær møter de i hverdagen? Er måten de møter trærne i bøkene på påvirket av egne erfaringer med trær? Kan det tenkes at jentenes samhandling med trær, slik den er framstilt i tekstene, virker inn på elevenes tenkning om trær? Vil den skalerte oppmerksomheten som rettes mot samspillet mellom mennesker og trær gjennom de økokritiske litteratursamtalene, bidra til at elevene utvider sin forståelse av eller finner gjenklang for at mennesket inngår $\mathrm{i}$ et verdifellesskap med andre livsformer?

Den foreslåtte vekslingen mellom et detaljert og personlig blikk på tekstene og et overordnet drøftende fellesskaplig blikk som her er presentert, kan selvsagt gjennomføres og gjøres gjeldende for den samlete lesingen av tekstene. I stedet for å gå i detaljer om disse mulighetene her, skal jeg avslutningsvis, i tråd med Currys skalerte lesning, presentere noen mellom- og stor-skala-innspill til hvordan man i en økokritisk litteraturundervisning kan lede oppmerksomheten mot hvordan tekstene legger opp til sammenlikninger av trærnes og Heidi og Annes livssituasjon (mellom-skala), og hvordan denne oppmerksomheten kan føre til at leserne selv ønsker å delta aktivt i felleskap som vil verne og bevare blant annet trær og skog for å nå FNs bærekraftsmål (stor-skala).

Sammenlikningen av trærnes og Heidis og Annes livssituasjoner har som premiss at det som skiller planter, og herunder også trær, fra de fleste dyr, er at de er stedbundne og i særlig grad avhengige av sine omgivelser. Derfor har de også 
utviklet «complex sensory and regulatory systems that allow them to modulate their growth in response to ever-changing conditions» (Chamovitz, 2012, s. 4). Noe tilsvarende kan hevdes om barn. De er også i større grad enn voksne avhengige av sine omgivelser og må derfor ta i bruk sanseapparatet sitt for å regulere og tilpasse seg skiftende omgivelser. Den utfordringen det er å stadig tilpasse seg er også noe Anne gir eksplisitt uttrykk for når hun den første morgenen på Bjørkely må ta innover seg at hun kanskje ikke kan bli værende der fordi det egentlig var en gutt Marilla og Matthew hadde «bestilt» fra barnehjemmet. Etter at Anne har tatt frokostoppvasken, ber Marilla henne «gå ut og more seg» (Montgomery, 2014, s. 42). Anne blir først glad og forventningsfull, men kommer så på at det er en risiko ved det å gå ut:

'Jeg tør ikke gå ut,' svarte Anne [...] 'Om jeg ikke kan bli her, har det ingen hensikt at jeg begynner å bli glad i Bjørkely. Og om jeg går ut dit og blir kjent med alle trærne og blomstene og frukthagen og bekken, kommer jeg til å bli så glad i alt sammen, selv om jeg prøver å la det være. Det er vanskelig nok nå, så jeg vil ikke gjøre det enda verre. Jeg vil så gjerne gå ut, for jeg føler at alt sammen kaller på meg. 'Anne, Anne, kom ut til oss. Anne, Anne, vi vil ha en lekekamerat.' Men det er bedre å la det være. Det har ingen hensikt å bli glad i noe om du vet du skal rives bort fra det igjen, har det vel? [...]'. (Montgomery, 2014, s. 42-43)

Også i Heidi er planter og dyr en del av Heidis lekemiljø, eller blant hennes fellow species, og dermed også i tråd med Laist (2013) betydningsfulle for hvordan hun erfarer og forstår seg selv som menneske. Når det etter en tid blir bestemt at Heidi nærmest skal rykkes opp med sine nyslåtte røtter og sendes til byen (Frankfurt) for å være selskap for den jevnaldrende Klara som er lenket til rullestolen, blir det tydelig hvordan hun strever med å tilpasse seg det nye miljøet og hvordan hun, som en plante som søker lys, stadig søker mot de stedene der hun kan komme i kontakt med naturen. Når hun våkner i Frankfurt den første morgenen, løper hun straks til vinduet for å «se solen og jorden der ute» (Spyri, 2006, s. 85) fordi hun hos bestefaren «pleide å løpe til døren for å se hvordan været var ute, om himmelen var blå og om solen var oppe, om granene suste og om blomstene hadde åpnet seg» (Spyri, 2006, s. 85-86).

Disse eksemplene er bare to av flere som illustrerer hvordan det i de to tekstene legges til rette for at leseren kan gjøre seg tanker om hva nærhet til steder og natur innebærer. A komme i kontakt med en slik litterært artikulert tenkemåte der «[n]aturen er et eksistensielt anliggende» (Hverven, 2018, s. 10), vil kunne møte, men også nyansere, elevenes egne måter å formulere seg om natur på. Kanskje vil det også motivere elevene til å se seg selv som språklig bevisste økoborgere, det vil blant annet si som verbalt aktive deltakere i et fellesskap der forpliktelser og ansvar for å etablere eller opprettholde et økologisk samspill også er avhengig av at vi forstår de grunnleggende kulturelle mønstrene som former våre livserfaringer og vår omverdenforståelse. 


\section{Oppsummering og konklusjon}

I denne artikkelen har jeg argumentert for at koblingen mellom oppmerksom lesing av og økokritiske litteratursamtaler om barnelitteratur kan utvikle kritiske perspektiver på verbalspråklige framstillinger av flersanselige naturerfaringer og dermed være et viktig bidrag til økt bevissthet om økologisk samspill. Å tilegne seg en slik tekstkompetanse kan ha betydning for hvordan barn og unge er språklig rustet til å orientere seg i den overordnete klimadiskursen og for hvordan de vil forstå seg selv i rollen som økoborgere.

Artikkelen er et bidrag til et lite utforsket felt innenfor nordisk litteraturdidaktikk, men også et bidrag til økokritisk barnelitteraturforskning der det har vært mer fokus på forholdet mellom mennesker og dyr enn mellom mennesker og planter. I tillegg kan fokuset på hvordan norskfaget kan bidra til kunnskap om ulike naturerfaringer, være verdifullt for å kunne ivareta den intenderte tverrfagligheten i utdanning for bærekraftig utvikling. I den sammenheng kan artikkelen kanskje motivere norsk- og engelsklærere til å integrere spørsmål relatert til bærekraftig utvikling, særlig FNs bærekraftsmål, i litteraturundervisningen sin og dermed selv være med å forme bærekraftsbegrepet så vel som utdanningsmålene.

\section{Om forfatteren}

Nina Goga er professor i barnelitteratur ved Høgskulen på Vestlandet. Hun leder forskningsprosjektet Nature in Children's Literature and Culture. Siste utgivelse er antologien Ecocritical Perspectives on Children's Texts and Cultures (2018) som hun har redigert sammen med Lykke Guanio-Uluru, Bjørg Oddrun Hallås og Aslaug Nyrnes. Goga har ellers skrevet bøkene Kart i barnelitteraturen (2015) og Gå til mauren. Om maur og danning i barnelitteraturen (2013).

Institusjonstilknytning: Institutt for språk, litteratur, matematikk og tolking, Høgskulen på Vestlandet, Postboks 7030, 5020 Bergen.

E-post: nina.goga@hvl.no

\section{Referanser}

Ahlbäck, P. M. (2010). Väderkontraktet: plats, miljörättvisa och eskatologi i Astrid Lindgrens Vi på Saltkråkan. Barnboken, 33(2), 5-18. doi: http://dx.doi.org/10.14811/clr.v33i2.17 Alexander, R (2008). Towards dialogic teaching: rethinking classroom talk. Cambridge: Dialogos.

Ask, L. (2016). Du. Oslo: Gyldendal.

Bache-Wiig, H. (2010). Fra Sveits til Glimmerdal: Maria Parrs Tonje Glimmerdal - en gjenskaping av Johanna Spyris Heidi? Barnelittercert forskningstidsskrift,1(1), Art. 3. doi: http://dx.doi.org/10.3402/blft.v1i0.5872 
Bakken, J. (2018). Máret Ánne Saras Mellom verdener (2014) og utdanning for bærekraftig utvikling. I S. Slettan (red.), Fantastisk litteratur for barn og unge (s. 231-253). Bergen: Fagbokforlaget.

Bartosch, R. (2014). Teaching a Poetic of Failure? The Benefit of Not-Understanding the Other, Posthumanism, and the Works of Shaun Tan and Wolf Erlbruch. In R. Bartosch \& S. Grimm (red.), Teaching Environments. Ecocritical Encounters (s. 59-73). Frankfurt am Main: Peter Lang Edition.

Bartosch, R. \& Grimm, S. (red.) (2014). Teaching Environments. Ecocritical Encounters. Frankfurt am Main: Peter Lang Edition.

Birkeland, T. (2016). Forhandling om natur - kultur. En økokritisk lesning av Jörg Müller og Jörg Steiners bildebok Kaninliv (1978). Barnelittercert forskningstidsskrift, 7(1), Art. 1. doi: http://dx.doi.org/10.3402/blft.v7.33705

Bland, J. (2014). Ecocritical Sensitivity with Multimodal Texts in the EFL/ESL Literature Classroom. In R. Bartosch \& S. Grimm (red.), Teaching Environments. Ecocritical Encounters (s. 75-96). Frankfurt am Main: Peter Lang Edition.

Chamovitz, D. (2012). What a Plant Knows. New York: Scientific American / Farrar, Straus and Giroux.

Curry, A. (2013). Environmental Crisis in Young Adult Literature: A Poetics of Earth. Basingstoke: Palgrave Macmillan.

Curry, A. (2017). A Question of Scale: Zooming out and Zooming in on Feminist Ecocriticism. I C. Beauvais \& M. Nikolajeva (red.), The Edinburgh Companion to Children's Literature (s. 70-78). Edinburgh: Edinburgh University Press.

Daniels, H. (2002). Literature Circles: Voice and Choice in Book Clubs and Reading Groups. Portland, ME: Stenhouse Publishers.

ENSCAN (u.å). ENSCAN. Hentet fra https://enscan.net/

Flanagan, V. (2014). Technology and Identity in Young Adult Fiction. Basingbroke: Palgrave Macmillan.

FN-sambandet (2018). FNs bœrekraftsmål. Hentet fra https://www.fn.no/Om-FN/FNsbaerekraftsmaal

Garrard, G. (2012a). Introduction. I G. Garrard (red.), Teaching Ecocriticism and Green Cultural Studies (s. 1-10). London: Palgrave Macmillan.

Garrard, G. (2012b). Ecocriticism. London og New York: Routledge.

Glotfelty, C. (1996). Introduction. I C. Glotfelty \& H. Fromm (red.), The Ecocriticism Reader. Landmarks in Literary Ecology (s. xv-xxxvii). Athens (Georgia) og London: The University of Georgia Press.

Goga, N. (2011). Enebarn eller litterært søsterskap? Om Heidi, Pippi og Tonje. I S. S. Botheim, I. R. Solbu, G. S. Botheim \& K. R. Solbu (red.), Søsken (s. 32-38). Oslo: Det Norske Samlaget.

Goga, N. (2016). Miljøbevissthet og språkbevissthet. Norsklæreren, 3, 60-72.

Goga, N. (2017a). A Feeling of Nature in Contemporary Norwegian Picturebooks. Encyclopaideia, 21(49), 81-97.

Goga, N. (2017b). I begynnelsen var treet. Økokritisk lesning av omformingen fra et stykke tre til gutt i Carlo Collodis Le avventure di Pinocchio. Storia di un burattino (1883). Barnelitteræert forskningstidsskrift, 8(1), Art. 4. doi: http://dx.doi.org/10.1080/20007493.2017.1308750

Goga, N, (2018a). Bærekraftig litteraturundervisning. I R. S. Stokke \& E. S. Tønnessen (red.), Møter med barnelitteratur (s. 351-369). Oslo: Universitetsforlaget.

Goga, N. (2018b). Interspecies Encounters - An Eco-Ethical Approach to Frida Nilsson's Ishavspirater (2015). I R. Hennig, A.-K. Jonasson \& P. Degerman (red.). Nordic 
Narratives of Nature and the Environment. Ecocritical Approaches to Northern European Literatures and Cultures (s. 157-170). London: Lexington books.

Goga, N. (2018c). Økofantasy. Frida Nilssons Ishavspirater (2015). I S. Slettan (red.), Fantastisk litteratur for barn og unge (s. 77-90). Bergen: Fagbokforlaget.

Goga, N., Guanio-Uluru, L., Hallås, B. O. \& Nyrnes, A. (red.) (2018). Ecocritical Perspectives on Children's Texts and Cultures: Nordic Dialogues. Basingstoke: Palgrave Macmillan UK.

Grimm, S. (2014). Ecodidactics? A German Perspective. In R. Bartosch \& S. Grimm (red.), Teaching Environments. Ecocritical Encounters (s. 247-259). Frankfurt am Main: Peter Lang Edition.

Guanio-Uluru, L. (under utgivelse). Education for Sustainability: Developing Eco-Critical Literature Circles in the Student Teacher Classroom. Discourse and Communication for Sustainable Education.

Guanio-Uluru, L. (2017). Katniss Everdeen’s Posthuman Identity in Suzanne Collins’s Hunger Games Series: Free as a Mockingjay? Jeunesse: Young People, Texts, Cultures, 9(1), 57-81.

Guanio-Uluru, L. (2018). Plant-Human Hybridity in the Story World of Kubbe. I N. Goga, L. Guanio-Uluru, B. O. Hallås \& A. Nyrnes (red.), Ecocritical Perspectives on Children's Texts and Cultures: Nordic Dialogues (s. 125-140). Basingstoke: Palgrave Macmillan UK.

Guanio-Uluru, L. (2019). Imagining Climate Change: The Representation of Plants in Three Nordic Climate Fictions for Young Adults. Children's Literature in Education. Hentet fra https://doi.org/10.1007/s10583-019-09387-4

Hennig, R., Jonasson A.-K. \& Degerman, P. (red.) (2018). Nordic Narratives of Nature and the Environment. Ecocritical Approaches to Northern European Literatures and Cultures. London: Lexington books.

Hennig, Å. (2012). Effektive lesere snakker sammen. Innføring i littercer samtale. Oslo: Gyldendal Akademisk.

Hole, S. (2015). Morkels alfabet. Oslo: Cappelen Damm.

Hverven, S. (2018). Naturfilosofi. Oslo: Dreyers forlag.

Håland, A. (2016). Skrivedidaktikk. Korleis støtta elevane si skriving i fag? Oslo: Universitetsforlaget.

Iversen, E. (2016). Klima, kriser og ulikhet. Om utsatte mennesker og områder i bildeboken Hvorfor er jeg her?. Masteroppgave, Høgskolen i Bergen.

James, E. (2012). Teaching Postcolonial/Ecocritical Dialogue. I G. Garrard (red.), Teaching Ecocriticism and Green Cultural Studies (s. 60-71). London: Palgrave Macmillan.

Jaques, Z. (2015). Children's Literature and the Posthuman: Animal, Environment, Cyborg. New York og London: Routledge.

Kidd, K. (2011). Classic. I P. Nel \& L. Paul (red.), Keywords for Children's Literature (s. 5258). New York og London: New York University Press.

Kjelen, H. (2013). Litteraturundervisning i ungdomsskulen. Kanon, danning og kompetanse. Doktoravhandling, Noregs teknisk-naturvitskaplege Universitet, Trondheim.

Kunnskapsdepartementet (2018). Kjerneelementer i fag. Hentet fra https://www.regjeringen.no/contentassets/3d659278ae55449f9d8373fff5de4f65/kjerne elementer-i-fag-for-utforming-av-lareplaner-for-fag-i-lk20-og-lk20s-fastsatt-av-kd.pdf

Kverndokken, K. (2012). 101 måter å lese leseleksa på: om lesing, lesebestillinger og tekstvalg. Bergen: Fagbokforlaget. 
Laakso, M., Lahtinen, T. \& Heikkilä-Halttunen, P. (2011). Tapion tarhoista turkistarhoille : luonto suomalaisessa lasten- ja nuortenkirjallisuudessa [Fra vill skog til pelsdyrindustri. Natur i finsk barne- og ungdomslitteratur]. Helsinki: Suomalaisen Kirjallisuuden Seura.

Laist, R. (2013). Introduction. I R. Laist (red.), Plants and Literature: Essays in Critical Plant Studies (s. 9-17). Amsterdam og New York: Rodopi B.V.

Larsen, P. S., Mønster, L. \& Rustad, H. K. S. (red.) (2017). Økopoesi. Alvheim og Eide akademisk forlag.

Lindström, E. (2008). I skogen. Stockholm: Alfabeta.

Marder, M. (2013). Plant-Thinking: A Philosophy of Vegetal Life. New York: Columbia University Press.

Massey, G. (2009). Reading the Environment: Narrative Constructions of Ecological Subjectivities in Australian Children's Literature. PhD Thesis, Queensland University of Technology.

Massey, G. \& Bradford, C. (2011). Children as Ecocitizens: Ecocriticism and Environmental Texts. I K. Mallan \& C. Bradford (red.), Contemporary Children's Literature and Film: Engaging with Theory (s. 208-217). Basingstoke: Palgrave Macmillan.

McKenzie. A. (2013). Patterns, Power, and Paradox. International Book Covers of Anne of Green Gables across a Century. I B. Lefebvre (red.), Textual Transformations in Children's Literature. Adaptations, Translations, Reconsiderations (s.127-153). New York and Oxon: Routledge.

Mercer, N. (2000). Words and Minds: How We Use Language to Think Together. Oxon and New York: Routledge.

Montgomery, L. M. (2014). Anne fra Bjørkely. Oslo: Transit.

Nilsson-Skåve, Å. (2015). "När det tar slut och börjar om igen”: Ekokritiska perspektiv på Stefan Castas ungdomsdystopier. Barnboken, 38. doi: http://dx.doi.org/10.14811/clr.v38i0.200

Ottesen, S. H. \& Tysvær, Aa. (2017). “Skjønnlitteratur for kosen”. Skjønnlitterære tekstpraksiser på mellomtrinnet, slik lærere forteller om dem. Norsklæreren, 4, 53-67.

Parr, M. (2009). Tonje Glimmerdal. Oslo: Det Norske Samlaget.

Penne, S. (2012). Hva trenger vi egentlig litteraturen til? Politikk, didaktikk og hverdagsteorier i nordiske klasserom. I N. F. Elf \& P. Kaspersen (red.), Den nordiske skolen fins den? Didaktiske diskurser og dilemmaer i skandinaviske morsmålsfag (s. 32-58). Oslo: Novus forlag.

Ratelle, A. (2015). Animality and Children's Literature and Film. Basingstoke: Palgrave Macmillan.

Rimmereide, H. E. (2013). Graphic novels in EFL learning. I A. Birketveit \& G. Willimas (red.), Literature for the English Classroom (s. 131-161). Bergen: Fagbokforlaget.

Røskeland, M. (2014). Litteratur i leseopplæringas teneste? Om litteraturfaget i skolen. I H. Gujord \& P. A. Michelsen (red.), Norsk Litterær Årbok 2014 (s. 195-211). Oslo: Det Norske Samlaget.

Røskeland, M. (2018). Natur i litteraturen. Økokritisk litteraturundervising med døme frå diktsamlinga Eg er eg er eg er. I K. Kverndokken (red.), 101 litteraturdidaktiske grep (s. 39-56). Bergen: Fagbokforlaget.

Samola, H. (2018). Botanics in Dystopian Environments. Human-Plant Encounters in Contemporary Finnish-Language Dystopian Fiction. I R. Hennig, A.-K. Jonasson \& P. Degerman (red.), Nordic Narratives of Nature and the Environment. Ecocritical Approaches to Northern European Literatures and Cultures (s. 137-155). London: Lexington books. 
Sinnes, A. T. (2015). Utdanning for bærekraftig utvikling. Hva, hvorfor og hvordan? Oslo: Universitetsforlaget.

Skrivesenteret (2013). Tenkeskriving i barneskolen. Hentet fra http://www.skrivesenteret.no/ressurser/tenkeskriving-i-grunnskolen/

Spyri, J. (2006). Heidi. Oslo: Aschehoug.

Sævareid, H. (2017). Bruddlinjer. Oslo: Gyldendal.

Ulland, G. (2016). Litteratursamtalens danningspotensial. Nordisk tidsskrift for pedagogikk og kritikk, 2(3), 97-110.

UNESCO (u.å.). What is Education for Sustainable Development? Hentet fra https://en.unesco.org/themes/education-sustainable-development/what-is-esd

Utdanningsdirektoratet (2017). Kjerneelementer - fag i grunnskolen og gjennomgående fag $i$ vgo. Hentet fra https://www.udir.no/laring-ogtrivsel/lareplanverket/fagfornyelsen/kjerneelementer/

Utdanningsdirektoratet (2018a). Hva er fagfornyelsen? Hentet fra https://www.udir.no/laringog-trivsel/lareplanverket/fagfornyelsen/nye-lareplaner-i-skolen/

Utdanningsdirektoratet (2018b). Tverrfaglige temaer. Hentet fra https://hoering.udir.no/Hoering/v2/197?notatId=344

Wistisen, L. (2018). Leken i antropocen: Skräpestetik i Barbro Lindgrens Loranga, Masarin och Dartanjang (1969) och Loranga, Loranga (1970). Barnboken, 41. doi: http://dx.doi.org/10.14811/clr.v41i0.316

World Commission on Environment and Development (1987). Vår felles framtid. Oslo: Tiden Norsk forlag.

Aase, L. (2005). Litterære samtalar. I B. K. Nicolaisen \& L. Aase (red.), Kulturmøte i tekstar. Litteraturdidaktiske perspektiv (s. 106-124). Oslo: Samlaget. 